\title{
Association of B-Type Natriuretic Peptide Levels With Estimated Glomerular Filtration Rate and Congestive Heart Failure
}

\author{
Carmen L. Wiley, PhD; Sean P. Switzer, DO; Richard L. Berg, MS; \\ Ingrid Glurich, PhD and Richard A. Dart, MD
}

\begin{abstract}
Background: The causes of elevated B-Type natriuretic peptide (BNP) levels are multifactorial. Renal dysfunction has been shown to affect BNP levels in some studies and the diagnostic value of BNP levels in the presence of chronic kidney disease has been questioned. Prior studies have involved small patient populations with variable outcomes noted. This study evaluated the association of BNP levels with an estimated glomerular filtration rate (eGFR) and presence or absence of congestive heart failure (CHF).

Methods: A retrospective, cross-sectional study in which medical records were electronically screened, identified patients with a BNP level and serum creatinine measurement on the same day between December 2002 and March 2006.

Results: Of 1739 eligible patients, 537 were positive for CHF and 1202 were negative for CHF by our criteria. There was a clear trend for BNP to be higher with the advancement of CHF, as determined by New York Heart Association (NYHA) classification $(P<0.00$ I). Median BNP levels increased from $65 \mathrm{pg} / \mathrm{mL}$ in patients without CHF to $496 \mathrm{pg} / \mathrm{mL}$ in patients with NYHA class IV CHF $(P<0.00 \mathrm{I})$, and there was a strong inverse association with eGFR $(P<0.00 \mathrm{I})$.

Conclusion: BNP levels show a strong inverse association with eGFR in both CHF and non-CHF patients. Currently best practice at most institutions involves use of BNP cutoff diagnostic levels not adjusted for eGFR. The data presented underlines that eGFR is a significant confounder of BNP measurement especially when renal status is compromised and interpretation of clinical significance in the presence of elevated BNP measures should take renal status into consideration.
\end{abstract}

Keywords: B-Type natriuretic peptide; Chronic kidney disease; Congestive heart failure;

Glomerular filtration rate

he natriuretic peptide (NP) system is a family of structurally similar but genetically distinct circulatory peptide hormones from either myocardial cell origin (atrial and B-type) or endothelial cell origin (C-type). The NP system functions in the regulation of blood pressure, and electrolyte and volume homeostasis. ${ }^{1}$ Binding of B-type natriuretic peptide (BNP) to its receptors in blood vessels or kidneys initiates diuretic, natriuretic, and vasorelaxant activities. Therefore, the cause of an elevated BNP level is multifactorial in origin and may reflect cardiac dysfunction, and/or changes in renal function. Atrial NP and BNP levels have been proposed as biomarkers for congestive heart failure (CHF), predictors of mortality and biomarkers for drug efficacy in patients with heart failure or left ventricular hypertrophy. ${ }^{2-4}$ Increased mortality in chronic renal failure is most frequently caused by congestive heart failure and/or coronary heart disease.$^{5-7}$ Since renal dysfunction intrinsically was shown to affect BNP levels in some studies, the diagnostic value of BNP levels in the presence of chronic kidney disease has been questioned.7,8 Prior studies have involved small patient populations and outcome data reported were variable. Thus, to contribute clinical value, BNP measurements need to be

E-mail: carmen.wiley@providence.org 
Table 1. BNP results by New York Heart Association classification.

\begin{tabular}{lccr}
\hline & & \multicolumn{2}{c}{ BNP (pg/mL) } \\
\cline { 2 - 3 } NYHA Class & N & Median & Interquartile Range \\
\hline No CHF & 1202 & 65 & $28-140$ \\
I & 116 & 285 & $130-516$ \\
II & 271 & 343 & $161-579$ \\
III & 115 & 427 & $249-747$ \\
IV & 35 & 496 & $248-1340$ \\
\hline
\end{tabular}

BNP, B-type natriuretic peptide; CHF, congestive heart failure; eGFR, estimated glomerular filtration rate.

explored within the context of renal function when developing patient treatment strategies. The goal of this study was to further evaluate the relationship between estimated glomerular filtration rate (eGFR) and BNP concentration in a large retrospective cohort of patients with varying levels of renal function.

\section{Methods}

A retrospective cross sectional study of BNP levels (TRIAGE BNP Test; Biosite Diagnostics) and GFR estimated from serum creatinine by the four-parameter MDRD equation 9,10 was conducted using electronic abstraction (programmed record review) in a large multi-specialty clinic and hospital in central Wisconsin for patients evaluated between December 2002 and March 2006. The study was approved by the institutional review board of the Marshfield Clinic Research Foundation (Marshfield, WI).

\section{Inclusion criteria}

Patients were included if they met the following criteria: (1) documentation of a BNP level and a serum creatinine measurement on the same day; (2) $\geq 18$ years of age on test date; and (3) validation of $\mathrm{CHF}$ status as non-CHF or $\mathrm{CHF}$ with classification by New York Heart Association (NYHA). Patients presented either as Clinic outpatients, in the hospital emergency room, or were hospital inpatients. Inpatients represented $36 \%$ of the total study population presented in this study. Patients were defined as having CHF only if they met all of the following requirements: (1) at least two ICD-9CM diagnosis codes for CHF (CHF exacerbation 428.0, and/ or systolic and diastolic heart failure 428.1-428.9, and/or volume / fluid overload 276.6) with at least 14 days between the first and the last; (2) at least one CHF diagnosis outside of the Emergency Room; (3) at least one diagnosis by a specialty provider (internal medicine, cardiology, or cardiac surgery); (4) at least one diagnosis within 5 days of the BNP measurement; and (5) recorded NYHA classification. Patients with no relevant diagnostic codes listed above for $\mathrm{CHF}$ were subset to the non-CHF group.

\section{Exclusion Criteria}

Patients showing a CHF-relevant diagnosis or a NYHA classification but not meeting the CHF criteria above were excluded from all analyses. Patients with renal failure were excluded if they showed Current Procedural Terminology codes for dialysis (90918-90925, G0312-G0327, 90935, 90937, 90945, and/or 90947) or any renal failure-related ICD-9-CM diagnostic codes (end stage renal disease 585, kidney transplant v42.0, hypertensive renal disease with renal failure 403.01, 403.11, 403.91, and/or hypertensive heart and renal disease and renal failure 404.03, 404.13, 404.93). Finally, patients were also excluded if they showed any pregnancy-related ICD-9-CM diagnostic codes.

Patient data was downloaded from the electronic medical record and electronically screened as detailed above. Some patients had more than one BNP result, often dependent on their status as inpatient or outpatient, but analyses were limited to the first available result, so each unique BNP value in this report reflects a unique patient. NYHA classifications

Table 2. Patient characteristics.

\begin{tabular}{|c|c|c|c|}
\hline & No CHF (n=1202) & Class I-II $(n=387)$ & Class III-IV $(n=150)$ \\
\hline Male & $48.8 \%$ & $50.6 \%$ & $49.3 \%$ \\
\hline Admitted to hospital & $36.0 \%$ & $35.9 \%$ & $40.0 \%$ \\
\hline $\begin{array}{l}\text { Age, years } \\
\text { median (range) }\end{array}$ & $71.5(18-102)$ & $80.3(37-99)$ & $80.6(32-100)$ \\
\hline $\begin{array}{l}\text { eGFR, mL/min } \\
\text { median (range) }\end{array}$ & $74.9(13-161)$ & $60.9(14-135)$ & $55.9(15-133)$ \\
\hline
\end{tabular}

$8 \quad$ BNP with eGFR and congestive heart failure 


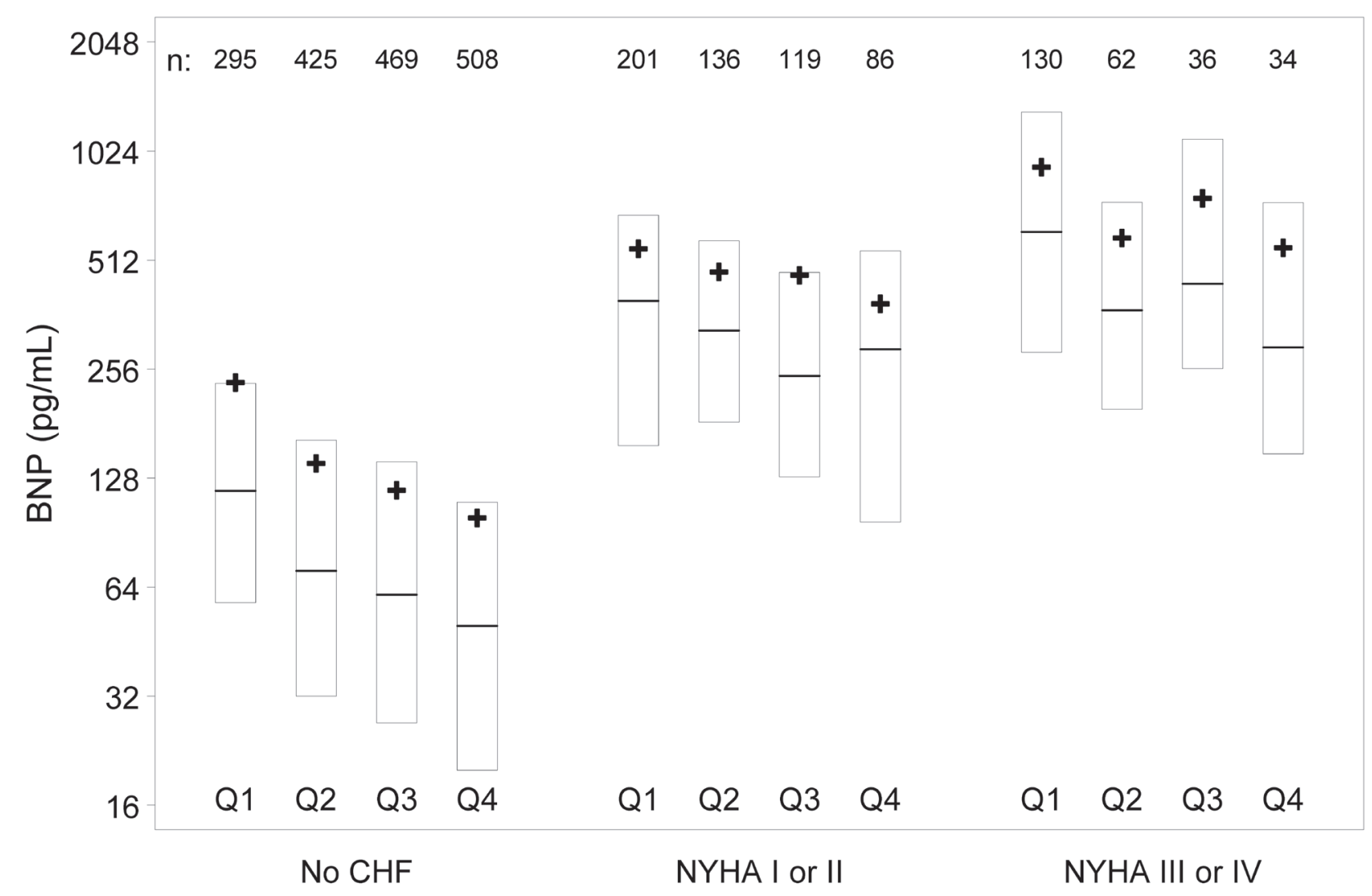

Figure 1. BNP by CHF group and eGFR quartile (Q1-Q4). Subjects within CHF group are divided by the overall eGFR distribution (eg, Q1 = lowest 25\% for eGFR in all groups, Q4 = highest 25\%). Within these eGFR subgroups, box plots extend from the $25^{\text {th }}$ to the $75^{\text {th }}$ percentile for BNP, with a bar at the median and a "+" indicating the subgroup mean BNP. The number of subjects in each subgroup is shown at the top of the figure. Increasing severity of underlying congestive heart failure was associated with increasing BNP $(P<0.001)$. In addition, there was a strong and highly significant inverse association between BNP and eGFR $(P<0.001)$, with higher BNP levels observed in those with lower eGFR.

I and II were combined, as were classifications III and IV, for most analyses to simplify the presentation. The primary analyses used general linear regression models (analysis of covariance). In these regression analyses, BNP was modeled as a function of eGFR and CHF classification. Models were tested for differences in the relation of BNP with eGFR (ie, the slope) between CHF and non-CHF patients. Adjustment for age and gender did not diminish the significance of the associations of BNP with eGFR and CHF, and age and gender were not included in the final models. Analyses of the residuals and predicted values from the regression models were evaluated to ensure that the models adequately represented the observed data, and both BNP and eGFR were first transformed in the final models by taking the natural logarithm to reduce skewness. The primary aim of these analyses was to establish the statistical significance of associations, rather than to determine the exact form of any existing relationships. Test results were reported as the observed significance levels ( $P$-values) for $\mathrm{F}$ tests from the analysis of covariance model for $\log (\mathrm{BNP})$ as a function of $\log (\mathrm{eGFR})$ and CHF classification, and were deemed significant at the $5 \%$ level $(P<0.05)$.

\section{Results}

Of 1739 eligible patients, 537 met criteria for CHF and 1202 met criteria as negative for CHF. BNP results within each NYHA classification are summarized in table 1. The NYHA classes were combined into three groups in table 2, which shows near equal numbers of men and women in all groups, but the CHF groups were somewhat older and with somewhat lower eGFR. As shown in figure 1, increasing severity of underlying congestive heart failure was associated with increasing BNP $(P<0.001)$. In addition, there was a strong and highly significant inverse association between BNP and eGFR $(P<0.001)$, with higher BNP levels observed in those with lower eGFR. This was true for both $\mathrm{CHF}$ and non-CHF patients, although the relationship was stronger in those without CHF.

\section{Discussion}

B-type natriuretic peptide belongs to a family of natriuretic proteins whose physiological role is maintenance of sodium homeostasis and protection of the cardiovascular system from volume overload. ${ }^{11}$ The biologically active form of BNP and the inactive amino terminal fragment NT-proBNP represent cleavage products of the precursor pre-proBNP which is 
synthesized by ventricular myocytes in response to physiological signals such as stretching of the ventricular wall, changes in systemic blood pressure, sodium levels or extracellular volume. To mediate its action, BNP is metabolized by specific natriuretic peptide receptors found in kidney, lung, liver, and along the vascular endothelium, while the NT BNP is mainly cleared by the kidneys. ${ }^{12}$

In a recent review, Vanderheyden et al ${ }^{13}$ observed that, despite the potential usefulness of both BNP and Nt-proBNP in diagnosis and management of patients with heart failure, including monitoring of response to drugs and a considerable body of literature exploring the usefulness of these biomarkers relative to these assessments, optimal strategies for their application in the clinical context remain undefined. The issue of how to differentially interpret BNP in the presence or absence of $\mathrm{CHF}$ and within the context of renal function has received considerable attention but remains incompletely resolved from a clinical perspective. Currently, clinical decisions which incorporate BNP results are made without formal adjustment for renal function. However, viewed from the physiological perspective of their function and clearance, changes in either renal or cardiac function could potentially impact NP levels and incomplete knowledge of the patient clinical status relative to degree of cardiac pathology or renal function could confound interpretation of BNP levels during evaluations of an acute event. ${ }^{12}$

Studies like the one by Masson et al ${ }^{14}$ of a cohort of 3916 patients with heart failure, suggested that BNP and NT BNP were independent markers correlating strongly with outcomes of CHF including: mortality, morbidity and hospitalization. Other factors which correlated with BNP levels reported by these authors included age, NYHA class, ventricular function, body mass index, cardiac arrhythmia, ischemia, diurtetics, bilirubin, creatinine, and C-reactive protein. In their study of 213 subjects, Vickery et $\mathrm{al}^{15}$ were among the first investigators to demonstrate that as renal function declined, BNP levels increased, especially among the subset of patients with ventricular hypertrophy. DeFilippi et al ${ }^{16}$ similarly found that among 389 patients with and without decompensated heart failure, those with eGFR $>60 \mathrm{~mL} / \mathrm{min} / 1.73 \mathrm{~m}^{2}$ had lower BNP levels than patients whose eGFR $<60 \mathrm{~mL} / \mathrm{min} / 1.73 \mathrm{~m}^{2}$. Outcomes of other studies ${ }^{17,18}$ however, suggested to Tagore et $\mathrm{al}^{19}$ that the relationship between renal function and BNP levels may be most strongly dependent on cardiac and volume-related factors. To test this hypothesis, these investigators studied BNP levels in a cohort of 143 clinically euvolemic patients with chronic kidney disease in whom absence of heart disease was clinically validated. These authors concluded that plasma BNP levels were independent of GFR. ${ }^{19}$ Jourdian et $\mathrm{al}^{20}$ evaluated use of serial measures of BNP over time to evaluate response to angiotensin converting enzyme inhibitors, beta blockers and diuretics and demonstrated the potential utility of these measures in predicting death or hospitalization related to chronic heart failure. These authors excluded patients with chronic renal failure from their study. ${ }^{20}$ Suresh and Farrington ${ }^{21}$ conducted a study of BNP levels in dialysis patients and concluded that BNP levels were predictive of presence of left ventricular dysfunction, cardiac events and survival in the presence of end stage renal disease, suggesting that BNP levels may be informative across the full range of renal function and even in its absence. Mark et $\mathrm{al}^{22}$ also performed a study for which they recruited patients to cover a range of renal function including patients on hemodialysis $(n=55)$, with functional renal allografts $(n=53)$ and 188 patients separated into quartiles based on renal function as determined by creatinine clearance measures. Patients were further evaluated for heart function by echocardiography for presence of left ventricular hypertrophy, dilatation, systolic and/or diastolic dysfunction, pharmacological treatment and blood chemistry. These authors concluded that, across the spectrum of renal function represented in their population, GFR exceeded ventricular function as the more important determinant impacting serum BNP levels. These authors further noted that in addition to GFR, hypoalbuminemia, anemia, use of beta blockers and age were significant confounders of serum BNP levels as has also been reported by others. ${ }^{23-27}$ Although subgroups of the Mark et $\mathrm{al}^{22}$ study were small, the authors cautioned that diagnostic utility of BNP in the presence of deteriorating renal function may be compromised to some extent.

In the present study, BNP was modeled as a function of eGFR and $\mathrm{CHF}$ classification. Differences in the relationship of BNP with eGFR in the presence and absence of CHF were explored. Patients with diagnostic codes for end stage renal disease, renal transplants or those on dialysis were excluded from these analyses to allow for evaluation in the presence of varying degree of renal function. Our data corroborated that a strong and highly significant inverse association between BNP and eGFR $(P<0.001)$ was evident, with higher BNP levels observed as eGFR declined. In addition our study demonstrated that increasing severity of underlying congestive heart failure was associated with increasing BNP $(P<0.001)$. Our study population is one of the largest evaluated to date and demonstrated a clear and statistically significant relationship between BNP and eGFR, in patients both with and without heart failure. Data subset to NYHA classification subgroups based on disease severity were included to further demonstrate this relationship. Notably, adjustment for age and gender did not diminish the significance of the associations of BNP with eGFR and CHF in the present study.

Current literature has supported clear and convincing evidence of increasing BNP levels with worsening heart failure, but has lacked clear recommendations regarding renal function. Understanding the relationship of eGFR and BNP in the presence and absence of clinical heart failure is beneficial to clinicians' understanding and interpretation of BNP levels when making diagnostic and treatment decisions. Some studies have attempted to model variance contributed by factors impacting BNP levels. For example, Lukowicz et al ${ }^{25}$ reported that left ventricular mass and body surface area were 
more predictive of natriuretic protein levels than any other cardiac parameter evaluated by echocardiography. Their predictive model however, explained only $13 \%$ of variance associated with BNP levels. As in our study, Tagore et al ${ }^{19}$ found that age correlated with NP levels in univariate analysis but inherently provided no predictive value. Other factors contributing to variance included left ventricular mass/body surface area (7\%) and beta blocker usage (7\%). Notably, more than one third of variance associated with NT proBNP levels (not evaluated in the current study) was attributable to GFR. This is likely attributable to the fact the NT proBNP clearance, unlike BNP, occurs almost exclusively at the level of the kidney ${ }^{28}$ and would therefore be more sensitive to level of renal function than BNP. Still other studies have attempted to define sensitivity, specificity, negative and positive predictive value for specific endpoints related to outcome and cut point values for BNP across a range of renal function. For example, McCullough et al, ${ }^{29}$ in their initial report on 1666 patients enrolled in the 'Breathing Not Properly Study', reported only a weak correlation between BNP and GFR which influenced the optimal cut point for BNP, especially in patients with eGFR $>60 \mathrm{~mL} / \mathrm{min} / 1.73 \mathrm{~m}^{2}$. Similar cut points were reported by DeFilippi et $\mathrm{al}^{16}$ However, as reviewed by Yang et $\mathrm{al}^{30}$ in 2008, cut off ranges vary broadly (200 pg/ml to $2000 \mathrm{pg} / \mathrm{ml})$, and applicability differs across subsets of patients depending on cardiac and renal functional status. The goals of the present study did not include calculation of cut points or evaluation of sensitivity or specificity due to the limitations associated with the retrospective design and electronic data abstraction methodology discussed below.

While the strength of this study is the number of unique patient records reviewed, its limitations are its retrospective design and data abstraction performance using only an electronic approach. However, our medical records have previously demonstrated a high degree of accuracy relative to phenotypic development by application of electronic abstraction relative to cardiac disease $\mathrm{e}^{31-35}$ and reliable retrieval of laboratory data. This is reflected in the close parallels between patterns of eGFR, cardiac disease and BNP reported by Mark et $\mathrm{al}^{22}$ in a prospective population that was carefully characterized for cardiac function. However, we are well aware that diagnosing and classifying heart failure is difficult, and misclassification is not uncommon. In the present study, patients classified in the non-CHF group could actually have had mild to moderate forms of CHF, and this would attenuate the association we are demonstrating to some degree. However, we see a highly significant association even though we are not able to fully validate exclusion of undiagnosed CHF from the "non-CHF" group.

\section{Conclusion}

Our goal was to provide compelling evidence of the association of renal function and BNP, with the full expectation that additional prospective studies will be required to validate and better define this relationship. Ideally, clinicians need clear guidelines regarding BNP and heart failure that include consideration of eGFR. Currently most institutions, including our own, continue to use BNP cutoff diagnostic levels that have not been adjusted for eGFR. Our data emphasized that a single BNP measurement must be evaluated in conjunction with the entire clinical presentation, particularly the level of renal function.

\section{Acknowledgments}

The authors wish to thank Marie Fleisner and Alice Stargardt of the Marshfield Clinic Research Foundation Office of Scientific Writing and Publication for providing assistance in formatting and preparing the final manuscript.

\section{References}

1. Levin ER, Gardner DG, Samson WK. Natriuretic peptides. N Engl J Med 1998;339:321-328.

2. Burnett JC, Kao PC, Hu DC, Heser DW, Heublein D, Granger JP, Opgenorth TJ, Reeder GS. Atrial natriuretic peptide elevation in congestive heart failure in the human. Science 1986;231:1145-1147.

3. Yamada Y, Goto J, Yokota M. Brain natriuretic peptide is a sensitive indicator of impaired left-ventricular function in elderly patients with cardiovascular disease. Cardiology 1997;88:401-407.

4. Yamamoto K, Burnett JC Jr, Jougasaki M, Nishimura RA, Bailey KR, Saito Y, Nakao K, Redfield MM. Superiority of brain natriuretic peptide as a hormonal marker of ventricular systolic and diastolic dysfunction and ventricular hypertrophy. Hypertension 1996;28:988-994.

5. Schaubel DE, Parsons DA, Hall NI, Fenton SS. The Canadian Organ Replacement Register on renal replacement therapy. Nephrol News Issues 1997;11:23-24,35.

6. Takami Y, Horio T, Iwashima Y, Takiuchi S, Kamide K, Yoshihara F, Nakamura S, Nakahama H, Inenaga T, Kangawa K, Kawano Y. Diagnostic and prognostic value of plasma brain natriuretic peptide in non-dialysis-dependent CRF. Am J Kidney Dis 2004;44:420-428.

7. Vickery S, Price CP, John RI, Abbas NA, Webb MC, Kempson $\mathrm{ME}$, Lamb EJ. B-type natriuretic peptide (BNP) and aminoterminal proBNP in patients with CKD: relationship to renal function and left ventricular hypertrophy. Am J Kidney Dis 2005;46:610-620.

8. Mueller C, Laule-Kilian K, Scholer A, Nusbaumer C, Zeller T, Staub D, Perruchoud AP. B-type natriuretic peptide for acute dyspnea in patients with kidney disease: insights from a randomized comparison. Kidney Int 2005;67:278-284.

9. Levey AS, Greene T, Kusek JW, Beck GJ, for the MDRD Study Group. A simplified equation to predict glomerular filtration rate from serum creatinine. J Am Soc Nephrol 2000;11:155A.

10. Levey AS, Coresh J, Greene T, Stevens LA, Zhang YL, Hendriksen S, Kusek JW, Van Lente F, Chronic Kidney Disease Epidemiology Collaboration. Using standardized serum creatinine values in the modification of diet in renal disease study equation for estimating glomerular filtration rate. Ann Intern Med 2006;145:247-254.

11. Daniels LB, Maisel AS. Natriuretic peptides. J Am Coll Cardiol. 2007;50:2357-2368.

12. Khalifeh N, Haider D, Hörl WH. Natriuretic peptides in chronic kidney disease and during renal replacement therapy: an update. J Investigative Med 2009;57:33-39.

13. Vanderheyden M, Bartunek J, Filippatos G, Goethals M, Vlem BV, Maisel A. Cardiovascular disease in patients with chronic renal impairment: role of natriuretic peptides. Congest Heart Fail 2008;14(4 Suppl 1):38-42. 
14. Masson S, Latini R, Anand IS, Vago T, Angelici L, Barlera S, Missov ED, Clerico A, Tognoni G, Cohn JN. Direct comparison of B-Type natriuretic peptide (BNP) and amino terminal proBNP in a large population of patients with chronic and symptomatic heart failure: the Valsartan Heart Failure (Val-HeFT) Data. Clin Chem 2006;52:1528-1538.

15. Vickery S, Price CP, John RI, Abbas NA, Webb MC, Kempson $\mathrm{ME}$, Lamb EJ. B-Type natriuretic peptide and amino terminal proBNP in patients with CKD: Relationship to renal function and left ventricular hypertrophy. Amer J Kidney Dis 2005;46:610-620.

16. deFilippi CR, Seliger SL, Maynard S, Christenson RH. Impact of renal disease on natriuretic peptide testing for diagnosing decompensated heart failure and predicting mortality. Clin Chem 2007;53:1511-1519.

17. Zoccali C, Mallamaci F, Benedetto FA, Tripepi G, Parlongo S, Cataliotti A, Cutrupi S, Giacone G, Bellanuova I, Cottini E, Malatino LS; CREED Investigators. Cardiac natriuretic peptides are related to left ventricular mass and function and predict mortality in dialysis patients. J Am Soc Nephrol 2001;12:1508-1515.

18. Takami Y, Horio T, Iwashima Y, Takiuchi S, Kamide K, Yoshihara F, Nakamura S, Nakahama H, Inenaga T, Kangawa $\mathrm{K}$, Kawano Y. Diagnostic and prognostic value of plasma brain natriuretic peptide in non-dialysis-dependent CRF. Am J Kidney Dis 2004 44: 420-428.

19. Tagore R, Ling LH, Yang H, Daw H-Y, Chan Y-H Sethi SK. Natriuretic peptides in chronic kidney disease. Clin J Am Soc Nephrol 2008;3:1644-1651.

20. Jourdain P, Jondeau G, Funck F, Gueffet P, Le Helloco A, Donal E, Aupetit JF, Aumont MC, Galinier M, Eicher JC, Cohen-Solal A, Juillière Y. Plasma brain natriuretic peptideguided therapy to improve outcome in heart failure: the STARS-BNP Multicenter Study. J Am Coll Cardiol 2007;49:1733-1739.

21. Suresh M, Farrington K. Natriuretic peptides and the dialysis patient Semin Dial 2005;18:409-419.

22. Mark PB, Stewart GA, Gansevoort RT, Petrie CJ, McDonagh TA, Dargie HJ, Rodger RS, Jardine AG. Diagnostic potential of circulating natriuretic peptides in chronic kidney disease. Nephrol Dial Transplant 2006;21:412-410.

23. Davis ME, Richards AM, Nicholls MG, Yandle TG, Frampton $\mathrm{CM}$, Troughton RW. Introduction of metoprolol increases plasma B-type cardiac natriuretic peptides in mild,stable heart failure. Circulation 2006;113:977-985

24. van den Meiracker AH, Lameris TW, van de Ven LL, Boomsma F. Increased plasma concentration of natriuretic peptides by selective beta1-blocker bisoprolol. J Cardiovasc Pharmacol 2003;42:462-468.

25. Lukowicz TV, Fischer M, Hense HW, Doring A, Stritzke J,Riegger G, Schunkert H, Luchner A; MONICA Investigators. BNP as a marker of diastolic dysfunction in the general population: Importance of left ventricular hypertrophy. Eur J Heart Fail 2005;7:525-531.

26. Kanda H, Kita Y, Okamura T, Kadowaki T, Yoshida Y, Nakamura Y, Ueshima $\mathrm{H}$. What factors are associated with high plasma B-type natriuretic peptide levels in a general Japanese population? J Hum Hypertens 2005;19:165-172.

27. Tsuji H, Nishino N, Kimura Y, Yamada K, Nukui M, Yamamoto $\mathrm{S}$, Iwasaka T, Takahashi H. Haemoglobin level influences plasma brain natriuretic peptide concentration. Acta Cardiol 2004;59:527-531.

28. Alehagen U, Lindstedt G, Eriksson H, Dahlström U. Utility of the amino-terminal fragment of pro-brain natriuretic peptide in plasma for the evaluation of cardiac dysfunction in elderly patients in primary health care. Clin Chem 2003; 49:1337-1346.
29. McCullough PA, Duc P, Omland T, McCord J, Nowak RM, Hollander JE, Herrmann HC, Steg PG, Westheim A, Knudsen CW, Storrow AB, Abraham WT, Lamba S, Wu AH, Perez A, Clopton P, Krishnaswamy P, Kazanegra R, Maisel AS; Breathing Not Properly Multinational Study Investigators. B-type natriuretic peptide and renal function in the diagnosis of heart failure: an analysis from the Breathing Not Properly Multinational Study. Am J Kidney Dis 2003;41:571-579.

30. Yang JW, Kim MS, Kim JS, Yoo JM, Han ST, Kim BR, Kim YD, Choi JW, Choi SO, Han BG. Relationship between serum brain natriuretic peptide and heart function in patients with chronic kidney disease. Korean J Intern Med 2008:23;191-200.

31. Vidaillet H, Granada JF, Chyou PH, Maassen K, Ortiz M, Pulido JN, Sharma P, Smith, PN, Hayes J. A population-based study of mortality among patients with atrial fibrillation or flutter. Am J Med 2002;113:365-370.

32. Granada J, Uribe W, Chyou PH, Maassen K, Vierkant R, Smith PN, Hayes J, Eaker E, Vidaillet H. Incidence and predictors of atrial flutter in the general population. J Am Coll Cardiol 2000; 36:2242-2246.

33. Greenlee R. Measuring disease frequency in the Marshfield Epidemiologic Study Area (MESA). Clin Med Res 2003;1:273-280.

34. DeStefano F, Eaker ED, Broste SK, Nordstrom DL, Peissig PL, Vierkant RA, Konitzer KA, Gruber RL, Layde PM. Epidemiologic research in an integrated regional medical care system: the Marshfield Epidemiologic Study Area. J Clin Epidemiol. 1996;49:643-652.

35. Wilke RA, Berg RL, Peissig P, Kitchner T, Sijercic B, McCarty CA, McCarty DJ. Use of an electronic medical record for the identification of research subjects with diabetes mellitus. Clin Med Res. 2007;5:1-7.

\section{Author Affiliations}

Carmen L. Wiley, PhD*; Sean P. Switzer, DO'; Richard L. Berg, MSł; Ingrid Glurich, PhD§; Richard A. Dart, MD\#

*Providence Sacred Heart Medical Center, Laboratory Medicine and Pathology, Spokane, WA; CentaCare Health System, St. Cloud, MN; Biomedical Informatics Research Center and \$Office of Scientific Writing and Publication, Marshfield Clinic Research Foundation, Marshfield, WI; \#Department of Nephrology, Marshfield Clinic, Marshfield, WI 